\title{
РАЗРАБОТКА ТРЕБОВАНИЙ К ПРОЦЕССАМ ОБРАБОТКИ ДАННЫХ ДЛЯ ЗАДАЧ УПРАВЛЕНИЯ В ДИСТАНЦИОННЫХ СИСТЕМАХ ВЫСШЕГО ОБРАЗОВАНИЯ
}

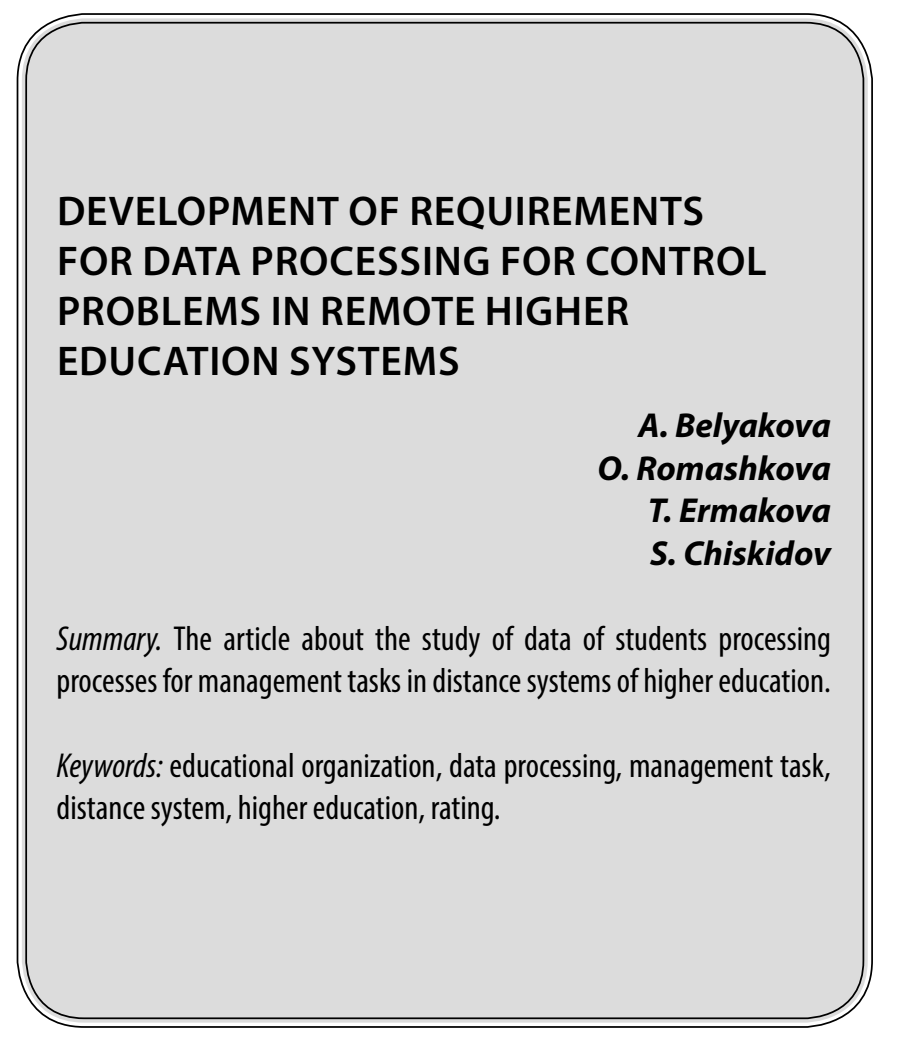

\section{Введение}

$\mathbf{H}$ а данный момент существует множество методик оценки как качества образования в образовательной организации, так и оценки достижений каждого обучающегося в отдельности. Эти методики зачастую не исключают присутствие человеческого фактора в случае, когда группа экспертов определяет вес показателей [1].

Например, если взять метод анализа иерархий, то для начала специалисту необходимо определить рейтинг каждого учебного, творческого, спортивного или иного достижения, оценить, насколько одно приоритетнее другого, в виде критерия (рисунок 1).

Таким образом, определяется приоритетность достижений при построении рейтинга. Однако возможно использовать искусственный интеллект для определения приоритета критериев.
Белякова Анна Вячеславовна

Аспирант, ГАОУ ВО «Московский городской педагогический университет (МГПУ)», г. Москва itwhitelight@mail.ru

Ромашкова Оксана Николаевна

Д.m.н., nрофессор, ГАОУ ВО «Московский городской педагогический университет (МГПУ)», г. Москва

ox-rom@yandex.ru

Ермакова Татьяна Николаевна

К.т.н., дочент, ГАОУ ВО «Московский городской педагогический университет (МГПУ)», г. Москва

ermaktat@bk.ru

Чискидов Сергей Васильевич

К.т.н., доцент, ФГБВОУ ВО «Академия гражданской защиты МЧС России»

Г. Химки (Московская обл.) chis69@mail.ru

Аннотация. Статья посвящена исследованию процессов обработки данных обучающихся для задач управления в дистанционных системах высшего образования.

Ключевые слова: образовательная организация, обработка данных, задача управления, дистанционная система, высшее образование, рейтинг.

На основе получения данных о рейтинге можно быстро сделать вывод о результатах управления и эффективности работы дистанционных систем высшего образования.

\section{Прочесс обработки $\triangle$ анных $\Delta \wedge$ за ач управления}

Было проведено моделирование процесса обработки данных для задач управления, представленное на рисунке 2.

Несмотря на возможность выбора SQLite3 по умолчанию для фреймворка web-приложения был сделан выбор в пользу Microsoft SQL Server.

\section{Определение рейтинга обучаюшихся}

Говоря о методе анализа иерархий как об одном из самых распространенных методов, зачастую роль 


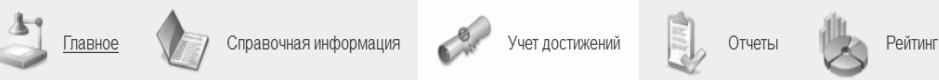

Регистрация учебных достижений Регистрация спортивных достижений Регистрация научныхдостижений Регистрация общественных достижений Регистрация творческих достижений Шкала отношений Создать -

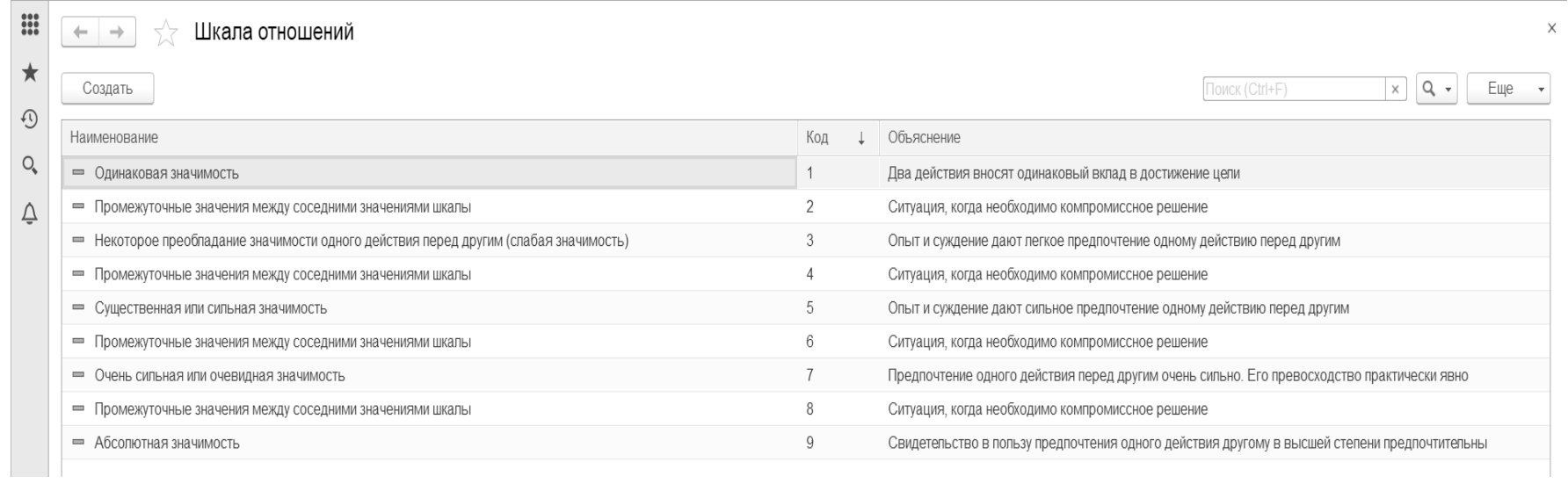

Рис. 1. Шкала отношений

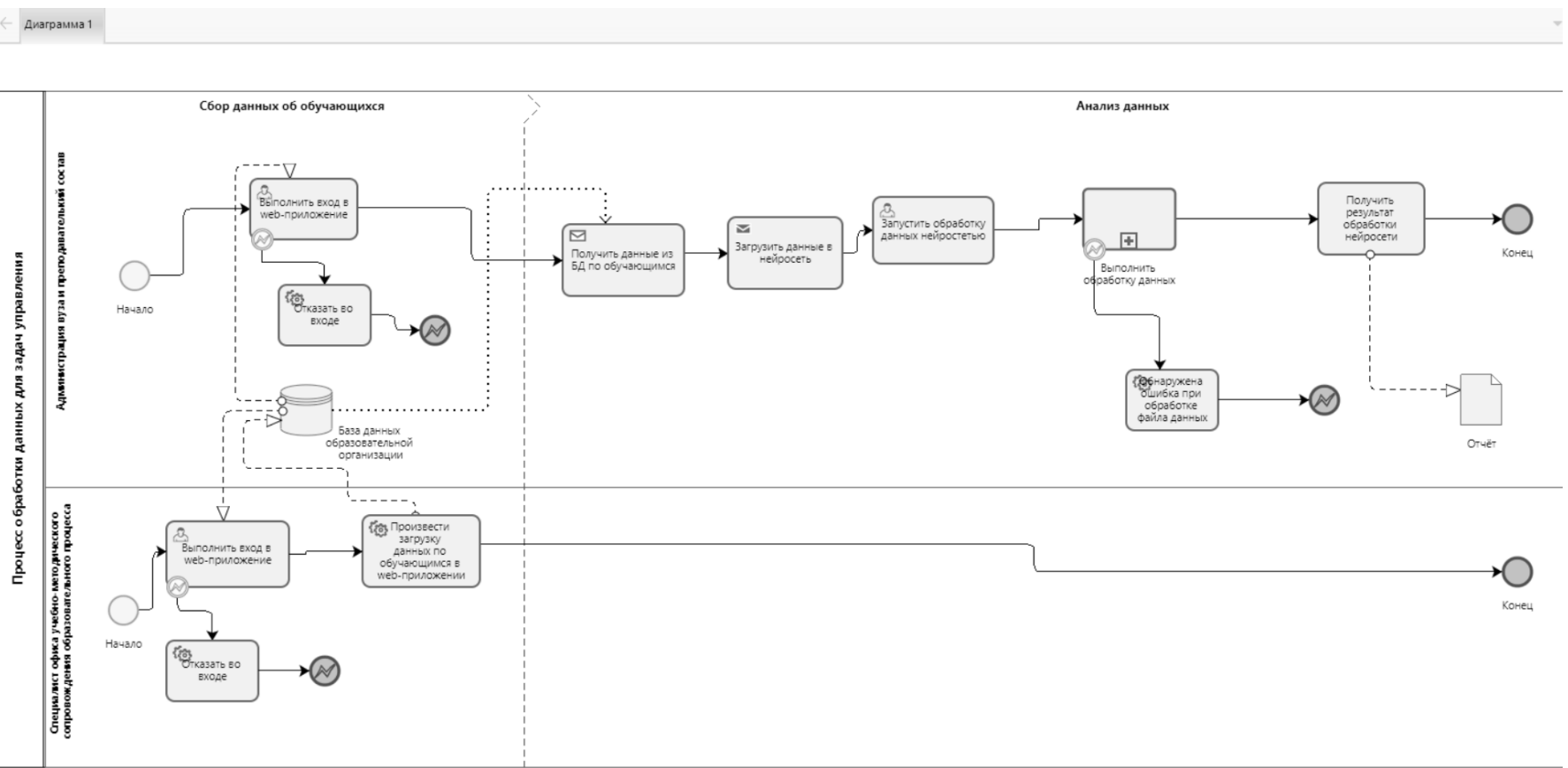

Рис. 2. Процесс обработки данных

экспертной оценки оставляют за скобками, сосредотачивая внимание на попарном сравнении альтернатив, построении матриц, вычислении векторов, расчете собственного значения и индекса согласованности, но все эти вычисления происходят на основе оценок, получен- ных в результате рассуждений эксперта, которые являются субъективными [2].

Для рейтинговой оценки достижений обучающихся в сетевых дистанционных системах высшего образова- 


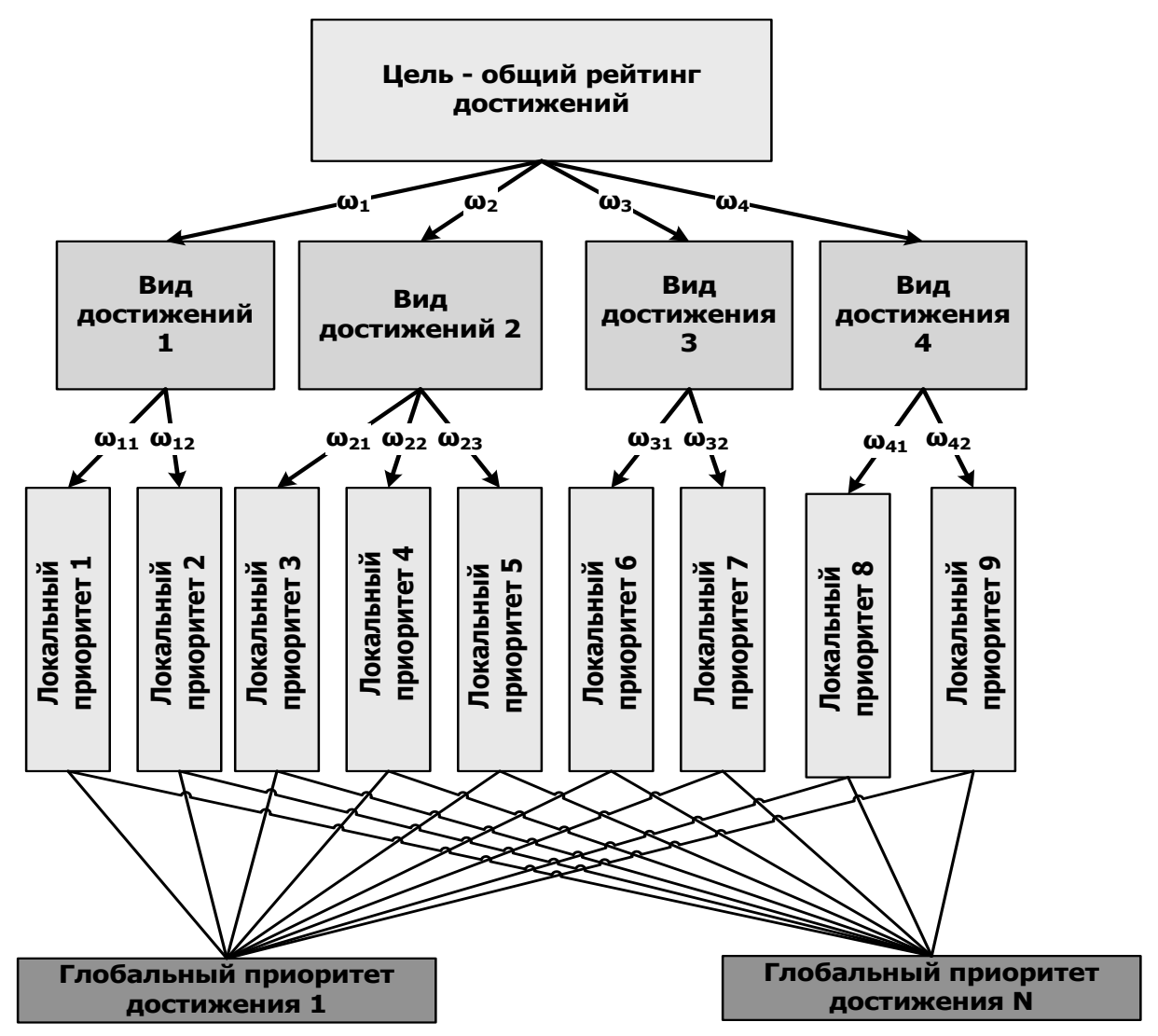

Рис. 3. Иерархическая структура

ния необходимо определить $\mathrm{n}$ весов критериев, а кроме этого, требуется активное участие эксперта в процессе определения весов всех достижений (рисунок 3).

В данной структуре всё основано на суждениях эксперта или группы экспертов. Из отношений суждений экспертов и получается матрица. Вектор приоритетов, получаемый в итоге, отражает то, насколько одно достижение приоритетнее другого.

Если для оценки эффективности управления образовательной организацией брать успехи обучающихся, то их достижения не только в учебной, но и в остальных видах деятельности, в частности, выступления на различных конференциях, публикации, необходимо также учитывать, и основанная на конкретных данных, например, на документах, публикациях, успеваемости оценка будет более объективна, чем, к примеру, социологические опросы, и может использоваться в следующих вариантах: 1) для выявления наиболее и наименее успешных образовательных программ; 2) для мотивации обучающихся путем предоставления повышенной стипендии или иных поощрений для наиболее успешных обучающихся; 3) дает полную картину для регулирования образовательной деятельности [3].
В качестве эксперта в образовательной организации может выступать специалист офиса учебно-методического сопровождения образовательного процесса на этапе введения в базу данных видов достижений, рейтинг которых будет храниться в ней (рисунок 4).

Затем суммарный рейтинг каждого обучающегося может быть получен как запросом из базы данных, так и через web-приложение (рисунок 5).

Загрузка данных о рейтинге обучающихся может производиться как при помощи средств Microsoft SQL Server, так и через web-приложение, к примеру, данные могут быть экспортированы из 1С: Предприятия в формате таблицы Excel и импортированы средством Microsoft SQL Server (рисунок 6, 7).

Возможно формирование целой экспертной группы для определения приоритетов согласно шкале Саати, однако очевидно быстрее и более экономически выгодно использование нейросети для определения приоритетов вместо эксперта или экспертной группы.

В процессе управления образовательной организацией может потребоваться получить оценку немедлен- 


\begin{tabular}{|c|c|c|c|}
\hline \multicolumn{4}{|c|}{ MSI.БДОбучающиеся-dbo.Виды_СД $\mapsto \times$} \\
\hline & Код_вида_СД & Название_СД & Рейтинг_СД \\
\hline \multirow[t]{17}{*}{ 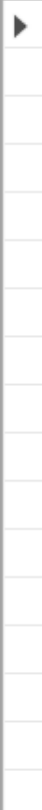 } & 1 & Лыжный спорт & 2 \\
\hline & 2 & Бer & 5 \\
\hline & 3 & Плавание & 3 \\
\hline & 4 & Гольф & 4 \\
\hline & 5 & Настольный теннис & 6 \\
\hline & 6 & Теннис & 9 \\
\hline & 7 & Волейбол & 7 \\
\hline & 8 & Футбол & 1 \\
\hline & 9 & Баскетбол & 3 \\
\hline & 10 & Каратэ & 6 \\
\hline & 11 & Дзюдо & 2 \\
\hline & 12 & Художественная гимнастика & 8 \\
\hline & 13 & Спортивная гимнастика & 2 \\
\hline & 14 & Спортивные танцы & 1 \\
\hline & 15 & Конное поло & 5 \\
\hline & 16 & Биатлон & 4 \\
\hline & 17 & Хоккей & 6 \\
\hline
\end{tabular}

Рис. 4. Достижения в базе данных

\section{Обучающиеся}

Список обучающихся также доступен на отдельной странице

Перейти »

\begin{tabular}{ll} 
Фи० Рейтинг \\
\hline
\end{tabular}

\begin{tabular}{l|c}
\hline Абакумова Наталья Петровна & 5 \\
\hline Абашин Алексей Антонович & 8 \\
\hline Авдеев Александр Александрович & 24 \\
\hline Авдеев Евгений Александрович & 5 \\
\hline Адидовских Артур Петрович & 2 \\
\hline Аксаненко Светлана Владимировна & 4 \\
\hline Андреев Антон Валерьевич & 11 \\
\hline Антиопова Лена Евгеньевна & 15 \\
\hline Апрель Алина Алексеевна & 4 \\
\hline Ахматова Алина Дмитриевна & 5
\end{tabular}

Рис. 5. Рейтинг в web-приложении 


\section{Рейтинг обучающихся (Основной)}

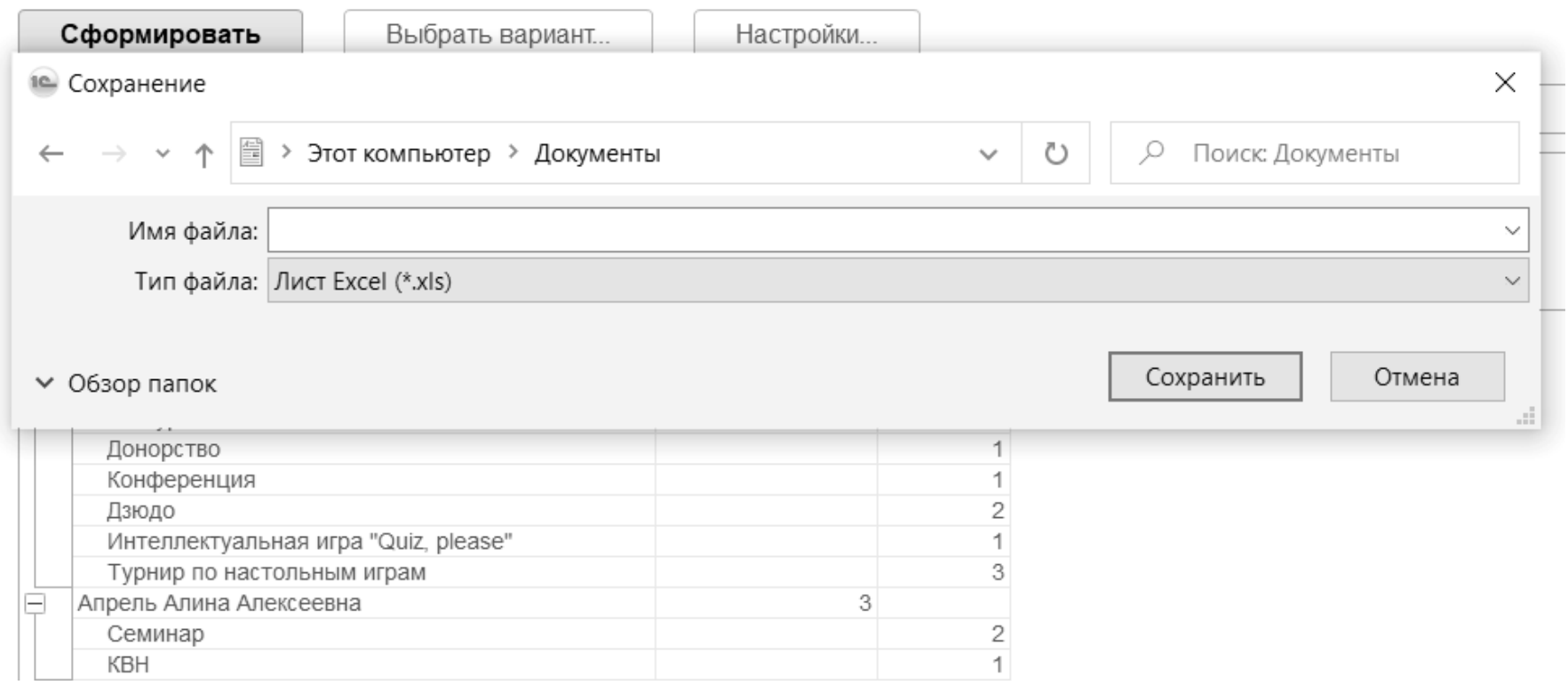

Рис. 6. Экспорт данных об обучающихся

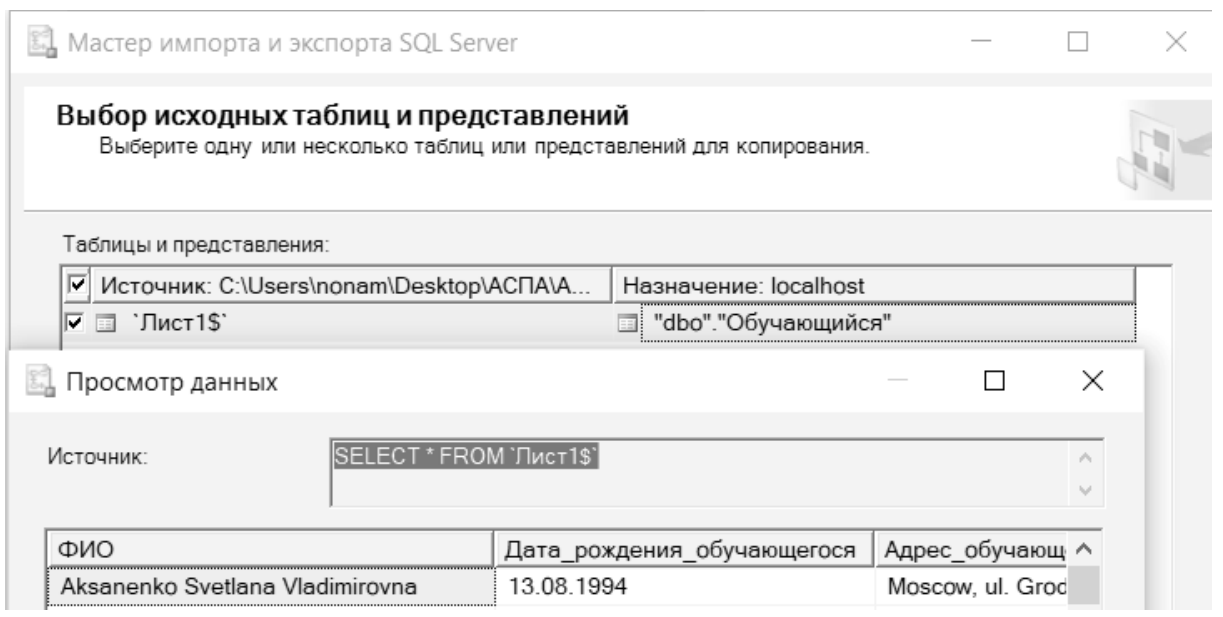

Рис. 7. Импорт данных об обучающихся

но, но при добавлении нового вида достижений обучающихся будет необходимо для начала привлечь эксперта или группу экспертов для оценки, что замедлит её получение, либо исключить этот вид достижений из анализа, что снизит объективность представленной картины [4].

\section{Опрехеление приоритетов с помошью обученной нейросети}

Если экспертные оценки уже существуют, то эти оценки даются в качестве обучающего набора (рисунок 8), и нейросеть таким образом решает задачу классификации - отнесения какого-либо вида достижения к определенному классу, более или менее приоритетному по шкале отношений Саати. Происходит сопоставление входных данных о достижениях с определенным классом.

Если эксперт до этого не привлекался, то нейросеть решает задачу группировки видов достижений по кластерам (рисунок 9), для этого в качестве числового значения, определяющего каждый вид достижений обуча- 


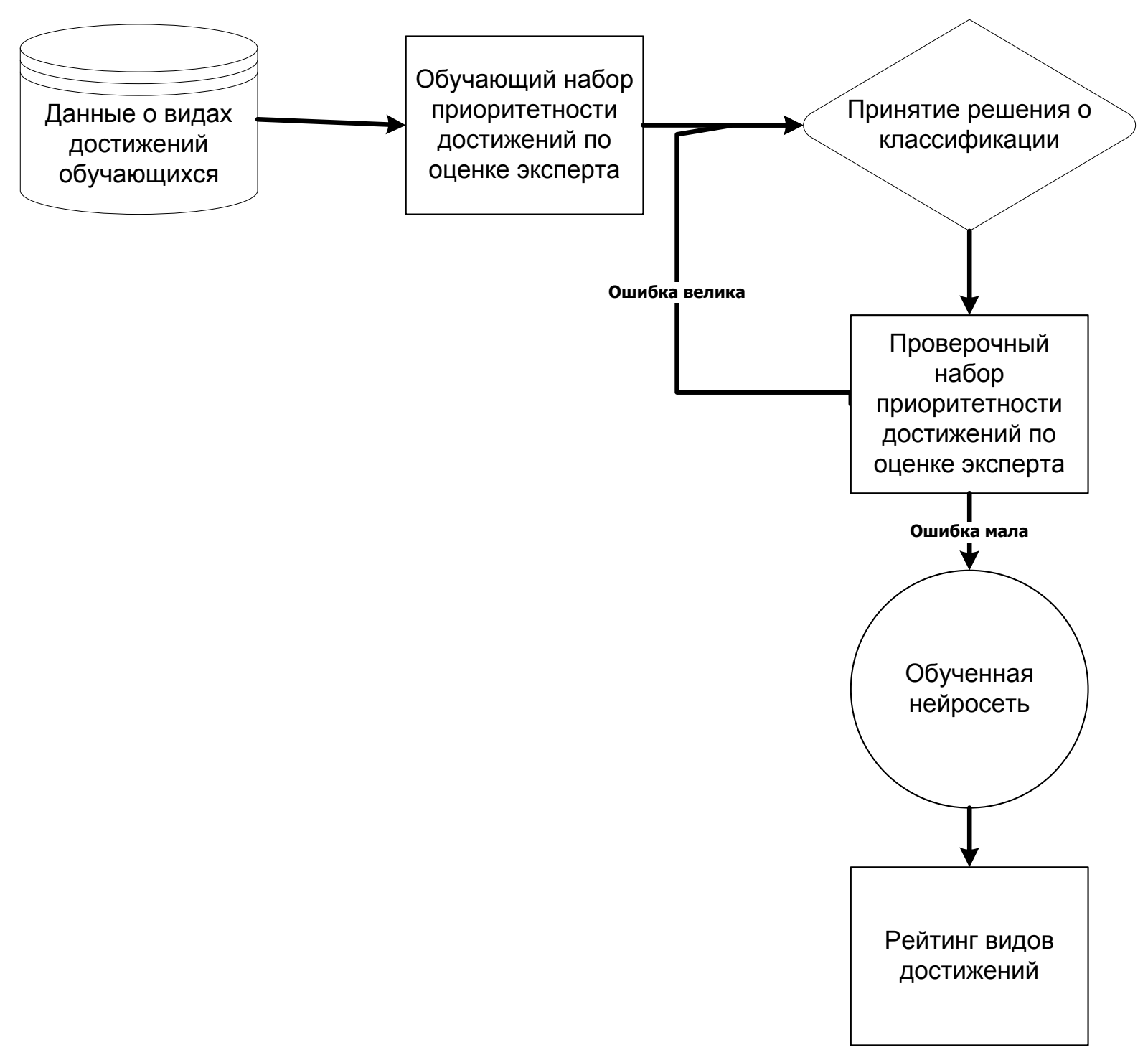

Рис. 8. Задача классификации

ющегося, берется количество обучающихся, у которых есть этот вид достижения, а в качестве меток кластеров опять же используется шкала отношений Саати, так что впоследствии будет возможно применить метод анализа иерархий в обоих случаях. Группировка маркировок по кластерам проходит без проверочного набора.

Использование именно шкалы отношений Саати необходимо, в частности, для того, чтобы у всех образовательных организаций была одинаковая шкала отношений, что могло бы дать возможность сравнивать показатели разных организаций или разных институтов внутри одного университета.

Поскольку необходимо обеспечить наиболее быструю обработку данных для задач управления в web-приложении дистанционной системы высшего образования, возможно использование в web-приложении функции заполнения нейросетью пустых ячеек базы данных в фоновом режиме, то есть после добавления нового вида достижений нейросеть может приступать к задаче кластеризации при отсутствии экспертной оценки или классификации, если экспертная оценка есть [5].

Также необходимо создать возможность сохранять данные о рейтинге на определенный момент времени для того, чтобы в дальнейшем можно было проследить динамику эффективности выполнения задач управления образовательной организацией во времени.

\section{Зак^ючение}

Таким образом, был проведен анализ процессов обработки данных для задач управления в дистанционных 


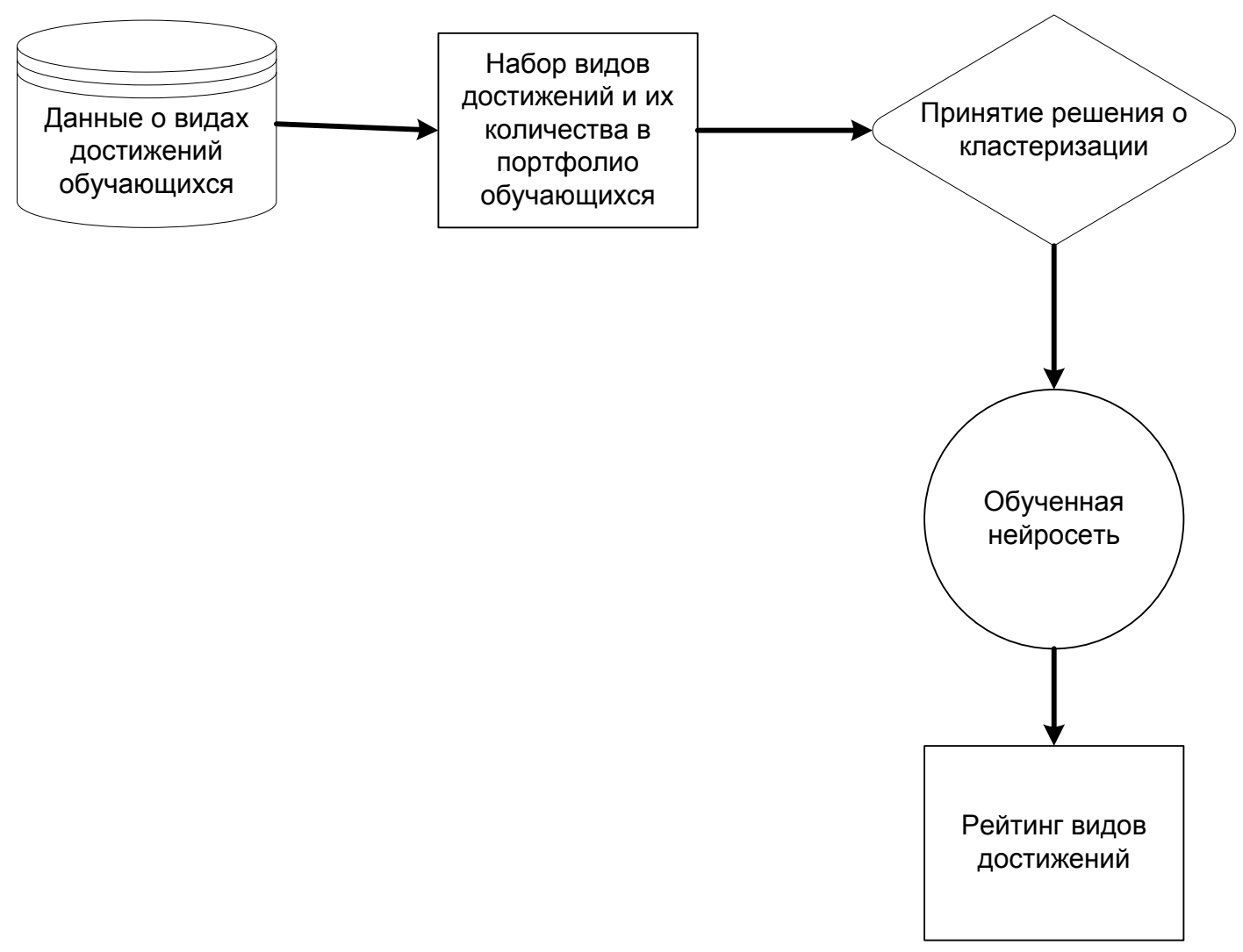

Рис. 9. Задача кластеризации

системах высшего образования. В дальнейшем необходимо разработать web-приложение, которое будет дистанционно получать и обрабатывать данные о рейтинге, и, используя эти данные, можно будет быстро сделать вывод о результатах управления и эффективности работы.

\section{ЛИТЕРАТУРА}

1. Белякова А.В., Пономарева Л.А., Ромашкова 0.Н. Математическая модель оценки качества образовательного процесса // В книге: Новые информационные технологии в научных исследованиях. Материалы XXIV Всероссийской научно-технической конференции студентов, молодых ученых и специалистов. 2019. C. 43-44.

2. Белякова А.В., Пономарева Л.А., Чискидов С.В. Прототип информационной системы оценки качества учебного процесса в образовательной организации // В книге: Новые информационные технологии в научных исследованиях. Материалы XXIV Всероссийской научно-технической конференции студентов, молодых ученых и специалистов. 2019. С. 45-46.

3. Romashkova 0.N., Belyakova A.V., Ponomareva L.A. Information model of data management in network online educational systems // В сборнике: Proceedings of the 2021 IEEE Conference of Russian Young Researchers in Electrical and Electronic Engineering, ElConRus 2021. 2021. C. 2226-2229.

4. Ермакова Т.Н., Ромашкова 0.Н., Пономарева Л.А. Модернизированная структура управления образовательной системой // Вестник Брянского государственного технического университета. 2019. № 6 (79). С. 84-91.

5. Ромашкова 0.Н., Пономарева Л.А., Василюк И.П. Применение информационных технологий для анализа показателей рейтинговой оценки вуза // В книге: Информационно-телекоммуникационные технологии и математическое моделирование высокотехнологичных систем. Материалы Всероссийской конференции с международным участием. 2018. С. 65-68.

(с Белякова Анна Вячеславовна ( itwhitelight@mail.ru ), Ромашкова Оксана Николаевна ( ox-rom@yandex.ru ), Ермакова Татьяна Николаевна ( ermaktat@bk.ru), Чискидов Сергей Васильевич ( chis69@mail.ru).

Журнал «Современная наука: актуальные проблемы теории и практики» 